\title{
CONDIÇOES HIGIENICO-SANITÃRIAS DO LEITE PASTEURIZADO TIPO "B" VENDIDO NA CIDADE DE SÃO PAULO, SP (BRASIL), NO PERIODO DE FEVEREIRO A AGOSTO DE 1982
}

\author{
Renato Baruffaldi* \\ Thereza Christina Vessoni Penna* \\ Irene Alexeevna Machoshvili* \\ Lucia Eiko Abe*
}

BARUFFALDI, R. et al. Condiçōes higiênico-sanitárias do leite tipo "B" vendido na cidade de São Paulo, SP (Brasil), no período de fevereiro a agosto de 1982. Rev. Saúde públ., S. Paulo, 18: $367-74,1984$.

RESUMO: Procedeu-se ao levantamento das condições higiênico-sanitárias de amostras de leite pasteurizado tipo "B", na cidade de São Paulo, SP (Brasil), nos meses de fevereiro a agosto de 1982. Trinta e cinco por cento das amostras analisadas apresentaram contagens excedentes a $10^{4}$ psicrófilos $/ \mathrm{ml} ; 65 \%$, excedentes a $4,0 \times 10^{4}$ mesófilos $/ \mathrm{ml}$; e, $63 \%$ superiores a 2 coliformes $/ \mathrm{ml}$. As presenças de Escherichia coli e deStaphylococcus oureus foram confirmadas em $17,5 \%$ das amostras analisadas, respectivamente.

UNITERMOS: Leite, contaminação. Alimentos, microbiologia.

\section{INTRODUÇÃO}

O leite, secreção das glândulas mamárias de mamiferos, possui valor nutritivo inigualável. E consumido, universalmente, por quaisquer faixas etárias, sob a forma fluída ou de seus derivados. Constitui-se alimento de importância para crianças e convalescen. tes e participante de pelo menos uma refeição diária do indivíduo clinicamente sadio.

$\mathrm{Na}$ pecuária, a vaca assume papel de destaque na produção leiteira, gozando de universalidade indiscutível; e, em menor escala, a cabra, a ovelha e o búfalo fêmea ${ }^{13}$. Do ponto de vista comercial, o leite é um produto íntegro, oriundo da ordenha completa do úbere de uma ou mais vacas, desprovido de colostro. A cidade de São Paulo é abaste. cida com leite proveniente de várias regiōes, podendo-se considerar um litro de leite, de qualquer estabelecimento comercial, amostra significativa da mistura de leites que apresentem os mais variados problemas higiênicosanitários.
O leite destinado ao consumo nunca é isento, totalmente, de microrganismos, havendo limites tolerados do número máximo permitido de bactérias não patogênicas, por mililitro do produto ${ }^{9}, 10$.

Com o crescimento da demanda do produto tornou-se imperativo o tratamento do leite que garantisse melhor qualidade higiênica, sem alterar profundamente as propriedades físico-químicas.

$O$ beneficiamento do leite, através da pasteurizaçăo, requer o emprego correto do par tempo-temperatura de aquecimento mínimo necessário, para lesar a flora microbiana patogênica. $O$ processo de pasteurização do lei. te objetiva a higienização do mesmo.

A região da Grande São Paulo contribui com $28 \%$ do total de leite pasteurizado produzido no país ${ }^{12}$. $O$ consumo anual do leite tipo "B" no Brasil, em 1980, foi de 332.300 .000 litros $^{6}$; em 1981 foi de 354.723.000 litros ${ }^{7} ; e$ em 1982 foi de

\footnotetext{
* Do Departamento de Bioquímico-Farmacêutica da Faculdade de Ciências Farmacêuticas da Universidade de São Paulo - Caixa Postal 30.786 - 01000 - Szo Paulo, SP - Brasil.
} 
BARUFFALDI, R. et al. Condiçōes higiênico-sanitárias do leite pasteurizado tipo "B" vendido na cidade de Sáo Paulo, SP (Brasil), no período de fevereiro a agosto de 1982. Rev. Saúde públ., S. Paulo, 18: $367-74,1984$.

343.530.000 litros $^{8}$. O consumo de leite fluído de todos os tipos no Brasil, em 1980, foi de 2.625.766.000 litros $^{6}$; em 1981 foi de 2.989.247.000 litros $^{7}$; e, em 1982, foi de 3.339.045.000 litros 8 . Portanto, o consumo de leite tipo "B", no país, correspondeu à taxa de $12 \%$ do volume total de leite pasteurizado produzido no ano de 1982.

0 presente trabalho pretende estudar as condiç̧̄es higiênico-sanitárias do leite pasteurizado tipo " $B$ " consumido na cidade de São Paulo, no período de fevereiro a agosto de 1982.

A enumeração de microrganismos patógenos nos alimentos geralmente envolve méto. dos custosos, de difícil execução, mormente se o número destes não for apreciável ${ }^{2}, 3,5$. Os microrganismos indicadores são mais facilmente isolados e identificados. Sua presença no leite indica exposição do mesmo às condiçōes que favorecem a introdução de patógenos genu ínos nos alimentos.

O objetivo em pauta visa a pesquisa dos microrganismos psicrófilos, mesófilos, .termófilos, coliformes, Escherichia coli e Staphylococcus aureus.

\section{MATERIAL E MÉTODOS}

\section{Material}

Após sorteio dos estabelecimentos comerciais, localizados na Zona Sul da cidade de São Paulo, foram adquiridas as amostras de seis marcas de leite pasteurizado tipo "B", coletadas ao acaso, no período de fevereiro a agosto de 1982. As embalagens plásticas fo. ram transportadas ao laboratório, em recipientes de isopor contendo gelo, num perío. do inferior a 2 horas.

\section{Metodologia}

Chegando ao laboratório, cada amostra recebia um número de código. Em seguida, era homogeneizada, por inversão da embalagem plástica, por 25 vezes consecutivas, e submetida aos exames microbiológicos.

Alíquotas de $10 \mathrm{ml}$ da amostra de leite eram transferidas para $90 \mathrm{ml}$ de diluente es- téril obtendo-se, assim, diluição 1:10. A partir desta, e pelo mesmo procedimento, eram preparadas outras seis diluiçōes.

As determinações dos números de microrganismos psicrófilos, mesófilos e termófilos foram realizadas segundo recomendaçðes da American Public Health Association $(\mathrm{APHA})^{2}$, pelo método de semeadura em profundidade, e expressas em contagem de bactérias aeróbias facultativas psicrófilas, contagem padrão em placas e contagem de bactérias aeróbias facultativas termófilas. Alíquotas de um ml da amostra eram depositadas em triplicata, para cada diluição preparada, no fundo de placas de Petri esteriliza. das, sendo a seguir vertidos, em cada uma, $15 \mathrm{ml}$ de ágar peptona-caseina-glicose-extrato de carne, fundido e resfriado a $45^{\circ} \mathrm{C}$, seguidos de homogeneização. Após a solidificação do ágar, as três séries de placas eram in. cubadas, a $7^{\circ} \mathrm{C}$ por 10 dias, $32^{\circ} \mathrm{C}$ por $24 \mathrm{~h}$ e $55^{\circ} \mathrm{C}$ por $48 \mathrm{~h}$, visando o crescimento de psicrófilos, mesófilos e termófilos, respectivamente. As colônias desenvolvidas eram contadas, em intervalo máximo de $4 \mathrm{~h}$ após o término do período de incubação, utilizando-se contador Messgerät. Para as placas paralelas de mesma diluição, com colônias contadas entre 20 e 300 , calculava-se a média aritmética dos resultados registrados, expressa em termos de números de unidades formadoras de colônias para a diluição considerada.

As estimativas quantitativas de bactérias coliformes totais, fecais e Escherichia coli eram determinadas pela técnica do Número Mais Provável (NMP), recomendada pela $\mathrm{APHA}^{2,3}$ e International Comission on Microbiological Specifications for Foods (ICMSF) $^{5}$. Inoculava-se alíquotas de $1 \mathrm{ml}$ de diluiçzes em tubo de fermentação contendo caldo verde-brilhante-lactose-bile, incubado à temperatura de $32^{\circ} \mathrm{C}$, durante 24 e $48 \mathrm{~h}$. Do tubo que apresentava formação de gás, no tubo de Duhran invertido, trans. feria-se material à superfície de ágar EMB (Teague), incubado à temperatura de $35^{\circ} \mathrm{C}$ durante $24 \mathrm{~h}$; e, simultaneamente, para tubo de fermentação contendo caldo $E$. C., incubado à temperatura de $44,5{ }^{\circ} \mathrm{C}$, 
BARUFFALDI, R. et al. Condiçð̄es higiênico-sanitárias do leite pasteurizado tipo "B" vendldo na cidade de São Paulo, SP (Brasil), no período de fevereiro a agosto de 1982. Rev. Saúde públ., S. Paulo, 18: 367-74, 1984.

durante 24 e $48 \mathrm{~h}$, em banho-maria termostaticamente controlado (FANEM, Mod. 112). Do tubo, que apresentava formação de gás no tubo de Duhran invertido, transfe. ria-se material à superfície de ágar EMB (Teague), incubado a $35^{\circ} \mathrm{C}$ por $24 \mathrm{~h}$. Colô. nias características foram isoladas e repicadas em ágar TSI inclinado, incubado a $35^{\circ} \mathrm{C}$ durante $24 \mathrm{~h}$. Em seguida essas colônias foram submetidas às provas bioquímicas da ICMSF $^{5}$ para a identificação de Escherichia coli.

A enumeraçāo, o isolamento e a identificação de Staphylococcus aureus foram realizadas segundo recomendaçð̃es da $\mathrm{APHA}^{3}$. Era utilizado ágar seletivo para estafilococos, segundo Baird Parker, previamente vertido e solidificado em placas de Petri. À superffcie deste meio, alíquotas de $0,1 \mathrm{ml}$ de cada diluição preparada eram transferidas e espalhadas com o auxflio de bastão de vidro em forma de " $L$ ". Os meios semeados eram incubados à temperatura de $35^{\circ} \mathrm{C}$ por $24 \mathrm{e}$ $48 \mathrm{~h}$. As colônias típicas eram contadas entre 20 e 200 , com o auxílio de contador Messgerät; em seguida eram semeadas à superfície inclinada de ágar nutriente e em in. fusão de coração e cérebro, incubados à temperatura de $35^{\circ} \mathrm{C}$ durante $24 \mathrm{~h}$. Procediam-se, então, às reaçðes de identificação através da pesquisa de catalase e da prova da coagulase. Os resultados eram expressos em números de unidades formadoras de colônias de $S$. aureus por mililitro de leite analisado.

Todos os meios de cultura procederam do laboratório DIFCO.

\section{RESULTADOS E DISCUSSÕES}

Os teores microbianos obtidos nas amostras de leite pasteurizado tipo "B" são mostrados na Tabela.

Os microrganismos psicrófilos são capazes de se multiplicarem à temperatura de $7^{\circ} \mathrm{C}$ ou de armazenamento do leite pasteurizado ${ }^{14}$; de produzirem enzimas proteolíticas termoestáveis; e, em número elevado, alterarem a composição físico-química do produto. O Departamento de Inspeção de
Produtos de Origem Animal (DIPOA) ${ }^{9}$ determina que a contagem de psicrófilos no leite beneficiado tipo " $B$ " não deve exceder $10 \%$ do número de mesófilos presentes. Trinta e três por cento dos litros de leite analisados de diferentes marcas apresentavam-se fora do padrão. As enumeraçбes de psicrófilos nas amostras identificadas co. mo 13,22 e 35 apresentaram-se superiores a $3,0 \times 10^{5}$ por mililitro de produto. Segundo Adams e col. ${ }^{1}$, há evidências de que populaçoes a nível de $1,0 \times 10^{4}$ microrganismos psicrófilos por mililitro, encontradas em 35\% das amostras analisadas, podem vir a produzir cerca de 10 ou mais unidades de proteases termoestáveis, responsáveis por aroma, sabor indesejáveis e coagulação do produto, encurtando a vida útil do mesmo.

A contagem padrão em placas, realizada à temperatura de $32^{\circ} \mathrm{C}$, no leite, favorece o crescimento de bactérias patogênicas, termodúricas, deteriorantes $\mathrm{e}$ outras. $\mathrm{O}$ DIPOA $^{9}$ e a Comissão Nacional de Normas e Padroes para Alimentos (CNNPA) ${ }^{10}$ regulamentam que a contagem padrăo em placas máxima por mililitro de leite nāo deva exceder o limite tolerado de $4,0 \times 10^{4}$. Constatou-se que $65 \%$ das amostras analisadas apresentaram resultados superiores. Normalmente, os produtos que apresentam de $10^{6}$ a $10^{8}$ microrganismos por mililitro são sensíveis a sinais de deterioração ${ }^{15}$, indicando, por vezes, leite em natureza excessivamente contaminado, ausência de condiçōes sanitárias e de temperaturas adequadas de beneficiamento e/ou armazenamento. Nas amostras $13,22,35$ e 38 foram obtidas contagens a $10^{6}$ por mililitro de amostra, portanto suspeitas.

Panetta ${ }^{11}$ não considera os microrganismos termófilos como indicadores da presença de insalubridade do leite pasteurizado, ao comparar as contagens normalmente encontradas àquelas de outros grupos de germes, psicrófilos ou mesófilos. Basappa e col. ${ }^{4}$, porém, consideram-nos de relevante importância, nos leites esterilizados, porque os microrganismos esporoformadores termófilos săo responsáveis por degradação proteolítica do produto. $O$ 
BARUFFALDI, R. et al. Condiçōes higiênico-sanitárias do leite pasteurizado tipo " $B$ " vendido na cidade de São Paulo, SP (Brasil), no período de fevereiro a agosto de 1982. Rev. Saúde públ., S. Paulo, 18: -, 1984.

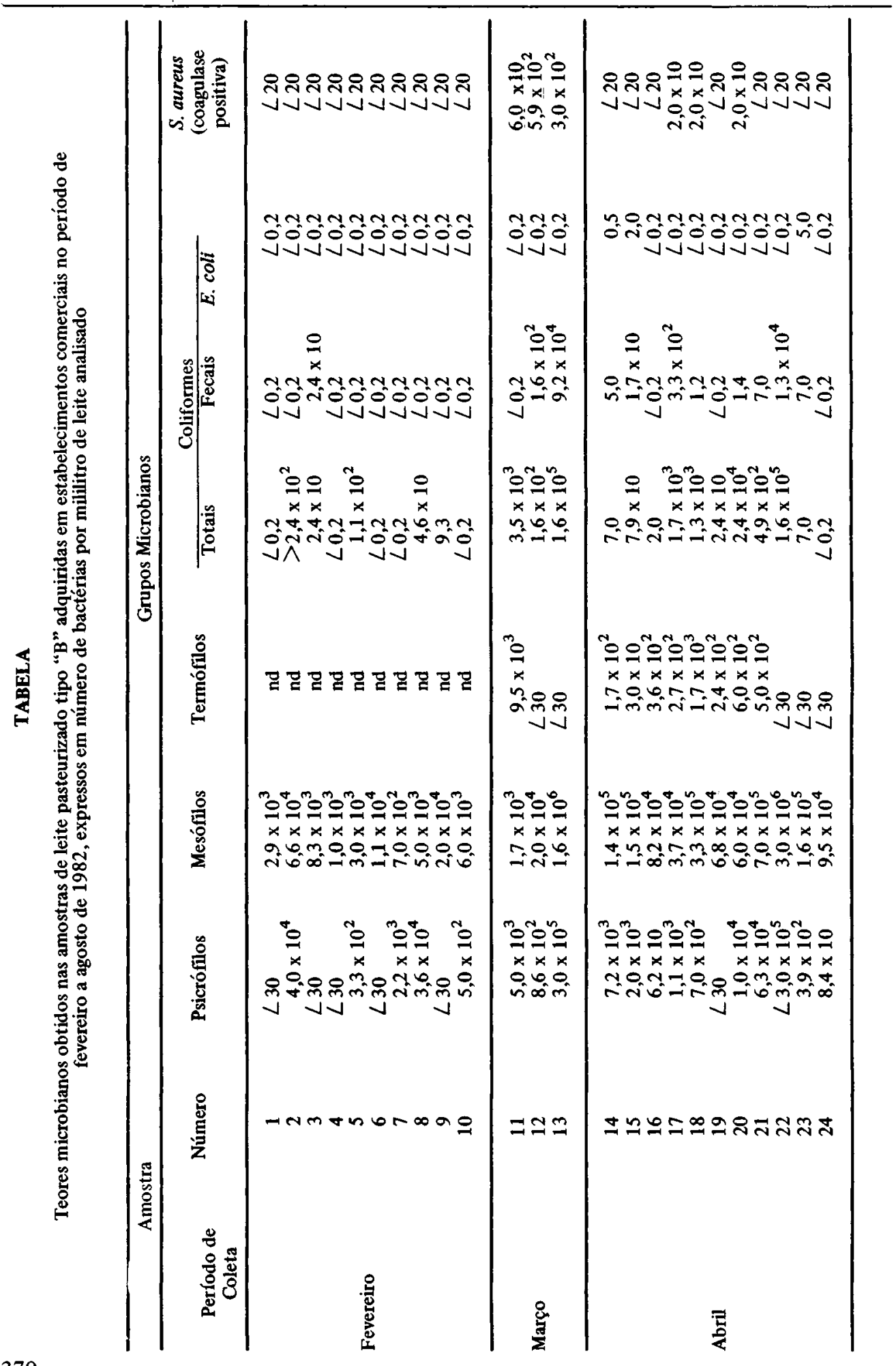


BARUFFALDI, R. et al. Condiçðes higiênico-sanitárias do leite pasteurizado tipo " $B$ " vendido na cidade de São Paulo, SP (Brasil), no período de fevereiro a agosto de 1982. Rev. Saúde pribl., S. Paulo, 18: $367-74,1984$.

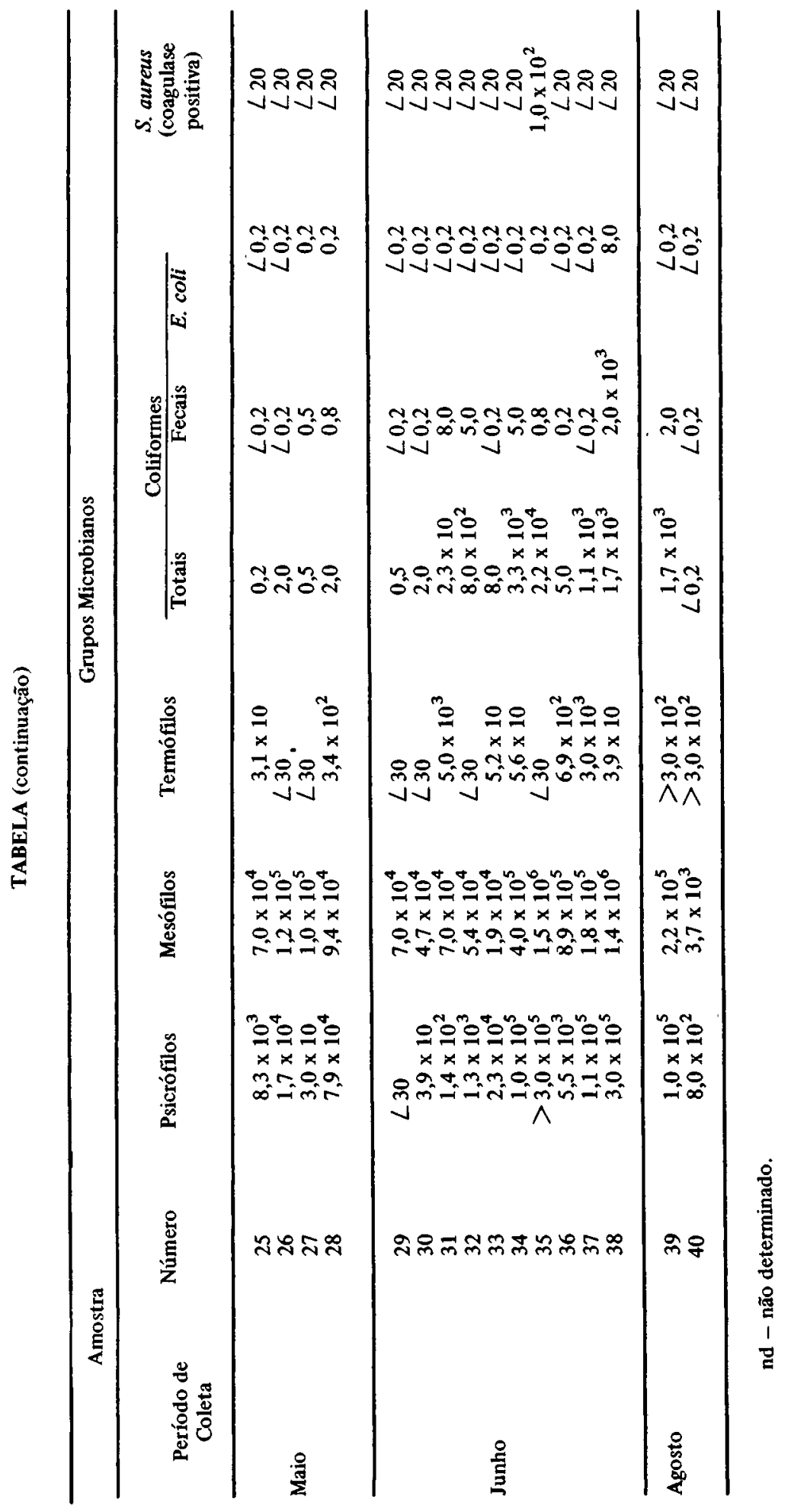


BARUFFALDI, $R$, et al. Condiçōes higiênico-sanitárias do leite pasteurizado tipo " $B$ " vendido na cidade de São Paulo, SP (Brasil), no período de fevereiro a agosto de 1982. Rev. Saúde pribl, S. Paulo, 18: $367-74,1984$.

DIPOA $^{9}$ determina que a contagem de bactérias aeróbias facultativas termófilas, no leite beneficiado tipo "B", não deve exceder $10 \%$ da contagem padrão em placas. Do total de amostras analisadas, um percentual de 2,5 apresentaram enumeração para termófilos excedentes.

O grupo de microrganismos coliformes totais é considerado indicadores das con. diçð̃es higiênicas da produção e beneficiamento do leite pasteurizado, apresentando fácil quantificação laboratorial. Os coliformes crescem bem em grande número de alimentos, ao intervalo de temperatura de $-2^{\circ} \mathrm{C}$ até $+50^{\circ} \mathrm{C}$; porém, ao intervalo de 5 a $7^{\circ} \mathrm{C}$ o desenvolvimento é lento $0^{2,3,5,15}$. O DIPOA $^{9}$ e a CNNPA ${ }^{10}$ regimentam limite de tolerância máximo de 2 coliformes por mililitro de leite pasteurizado tipo "B". Sessenta e três por cento das amostras analisadas apresentaram contagens excedentes. A média de coliformes encontrada por Panetta ${ }^{11}$, para leite pasteurizado tipo " $\mathrm{B}$ " na cidade de São Paulo, foi de $1,7889 \mathrm{x}$ $10^{4} / \mathrm{ml}$, enquanto que, no presente trabalho, apenas $10 \%$ atingiu ou superou tal valor.

O habitat natural da bactéria coliforme fecal de Escherichia coli é o trato entérico do homem e de outros animais de sangue quente. A presença da bactéria indica poluição fecal direta ou indireta, mas recente, como também a possível presença de patógenos entéricos como de salmonelas, de shige. las, de vibrios, de entamoebas, de vírus enté. ricos e de outros, que ocorrem nas áreas de produção e beneficiamento do leite. $O$ $\mathrm{DIPOA}^{9}$ não estabelece limites para o grupo de bactérias coliformes fecais porque tem finalidade de assegurar a qualidade do produto. $\mathrm{A} \mathrm{CNNPA}^{10}$ estabelece que deverá haver ausência desse grupo de microrganismos em um $\mathrm{ml}$ de leite pasteurizado tipo "B". As cepas de $E$. coli enteropatogênicas invasivas, toxigennicas e causadoras da gastro. enterite infantil (GEI) - são todas responsáveis por diarréia em crianças e adultos. Por medida de segurança, a presença de Escherichia coli torna o produto risco em potencial à saúde pública; sob este ponto de vista, rejeitar-se-iam $17,5 \%$ das amostras anali- sadas.

As cepas de Staphylococcus aureus, produtoras em potencial de enterotoxinas, quando presentes no leite beneficiado, mostram possivel contaminação pós-processamento oriunda do contacto humano pela pele, boca ou nariz com o alimento processa$\mathrm{do}^{15}$. Na ausência de resfriamento apropriado do leite contaminado ou beneficiado, esses organismos crescem e produzem enterotoxinas potentes, principalmente, na faixa de temperatura entre 27 e $49^{\circ} \mathrm{C}$. As enzimas termoestáveis são de detecção morosa e custosa em relação ao isolamento e identifi. cação de $S$. aureus no leite pasteurizado. É difícil acompanhar os gradientes de tempera. tura do leite em natureza até o beneficiamento e do produto pasteurizado, durante - transporte e presença no comércio. Por estas razōes a presença da bactéria $S$. aureus se constitui risco em potencial à saúde pública. Propõe-se que deva haver ausência desse grupo de microrganismos em um $\mathrm{ml}$ do leite pasteurizado tipo " $B$ ". De quarenta amostras analisadas, sete apresentaram positivas para a presença de $S$. aureus. De acordo com o critério proposto, essas amostras se. riam rejeitadas para o consumo.

\section{CONCLUSÕES}

Os resultados obtidos dos teores microbiológicos de psicrófilos, mesófilos e coli. formes apresentaram enorme variação, inde. pendentemente das marcas pesquisadas, mostrando que a qualidade higiênico-sanitária do leite pasteurizado tipo " $B$ " carece de me. lhores cuidados.

O sucesso para a obtenção de produtos pasteurizados, de qualidades nutritivas e higiênico-sanitárias ideais e constantes, está associado a programas de educação sanitária que deveriam ser difundidos em cada fa. se: obtenção, acondicionamento, pasteuriza. ção, transporte e distribuição do leite pasteurizado tipo " $\mathrm{B}$ ".

As qualidades bacteriológicas dos leites recém-ordenhados são próprias de cada região. A mistura dos leites de várias procedên- 
BARUFFALDI, R. et al. Condições higiênico-sanitárias do leite pasteurizado tipo " $B$ " vendido na cidade de São Paulo, SP (Brasil), no período de fevereiro a agosto de 1982. Rev. Saúde públ., S. Paulo, 18: $367-74,1984$

cias pode vir a comprometer a qualidade do lote final, pela introdução de teores microbianos diversos.

Ao produtor do leite cabe a responsabilidade pela qualidade do leite em natureza. A usina de beneficiamento deve tomar as medidas de precaução necessárias para manter essa qualidade do leite conseguida na área de produção, durante a utilização do produto.

0 armazenamento e expedição do leite pasteurizado empacotado deve ser à tem. peratura máxima de $5^{\circ} \mathrm{C}$ e comercializado em temperatura não superior a $10^{\circ} \mathrm{C}^{6}$. Os estabelecimentos comerciais necessitam ser esclarecidos e conscientizados da importân. cia da refrigeração do produto para a manutenção das características físico-químicas e microbiológicas do leite pasteurizado.
Sessenta e cinco por cento das amostras analisadas, comercializadas na Zona Sul do município de São Paulo, apresentaram contagem padrăo em placas superior a $4,0 \times 10^{4} / \mathrm{ml}$, significando leite em natureza excessivamente contaminado, subpasteurização, contaminação pós-processo ou exposição do produto beneficiado à temperatura superior a $10^{\circ} \mathrm{C}$.

A presença de $E$. coli e de $S$. aureus, em $17,5 \%$ das amostras analisadas, sugere cepas possivelmente resistentes à pasteurização; ou, uma das razōes apontadas para a presença de mesófilos. A presença de $S$. aureus em leite beneficiado deve indicar risco em potencial à saúde, visto produzirem enterotoxinas resistentes ao tratamento de pasteuriza. ção.

BARUFFALDI, R. et al. [Sanitary condition of "type B" pasteurized milk sold in S. Paulo city, SP (Brazil) in the period from February to August, 1982]. Rev. Saúde públ., S. Paulo, 18:367-74, 1984 .

ABSTRACT: Samples of type "B" pasteurized milk collected from different commercial establishments in S. Paulo, city, SP (Brazil) were subjected to microbiological inspection. Thirty-five percent of samples showed psychrotrophs exceeding $10^{4} / \mathrm{ml}$; sixty-five percent showed mesophilic counts exceedinf $4 \times 10^{4} / \mathrm{ml}$ and sixty-three showed more than two coliforms/ml. Escherichia coli and Staphylococcus aureus were found to occur in $17.5 \%$ of the material collected, respectively.

UNITERMS: Milk contamination. Food microbiology.

\section{REFERENCIAS BIBLIOGRÁFICAS}

1.ADAMS, D.M.; BARACH, J.T. \& SPECK, M.L. Heat resistant proteases produced in milk by psychrophilic bacteria of dairy origin. J. Dairy Sci., 58: 828-34, 1975.

2.AMERICAN PUBLIC HEALTH ASSOCIATION. Standard methods for the examination of dairy products. $13^{\text {th }}$ ed. Washington, D.C., 1972.

3.AMERICAN PUBLIC HEALTH ASSOCIATION. Compendium of methods for the microbiological examination of foods. $2^{\text {nd }}$ ed. Washington, D.C., 1976.
4.BASAPPA; P.; SHROFF, D.N. \& SRINIVASAN, R.A. Growth characteristics of thermophilic micro-organisms in milk. Indian J. Dairy Sci., $27:$ 103-8, 1974.

5.INTERNATIONAL COMMISSION ONMICROBIOLOGICAL SPECIFICATIONS FOR FOODS. Micro-organisms in foods. 1. Their significance and methods of enumeration. $2^{\text {nd }}$ ed. Toronto, University of Toronto Press, 1978.

6.LEITE e produtos lácteos sob inspeção federal - SIF - Brasil - 1980. Bol. Leite, S. Paulo, $53(637): 2-6,1981$. 
BARUFFALDI, R. et al. Conđiçð̋es higiênico-sanitárias do leite pasteurizado tipo " $B$ " vendido na cidade de São Paulo, SP (Brasil), no período de fevereiro a agosto de 1982. Rev. Saúde públ., S. Paulo, 18: $367 \cdot 74,1984$.

7.LEITE e produtos lácteos sob inspeção federal - SIF - Brasil - 1981. Bol. Leite, S. Paulo, $54(648): 2-6,1982$.

8.LEITE e produtos lácteos sob inspeção federal - SIF - Brasil - 1982. Bol. Leite, S. Paulo, 55 (655): 4-6, 18, 1983.

9.MINISTERIO DA AGRICULTURA. Departamento Nacional de Inspeçáo de Produtos de Origem Animal. Inspecção industrial e sanitária do leite e derivados; cap. 1: leite em natureza; Decreto n? 30.691 de 29 de março de 1952. In: Regulamento do inspeção industrial e sanitaria de produtos de origem animal. Brasília, s.d.

10.MINISTERIO DA SAOUDE. Comissáo Nacional de Normas e Padrōes para Alimentos. Resolução nọ 13/78 de 31 de março de 1978: aprova a revisăo dos padrōes microbiológicos. Diário Oficial de Uniāo, Brasília, 25 jul. 1978.

11.PANETTA, J.C. Avaliação de algumas características físico-químicas e microbiológicas de leites beneficiados distribuídos ao consumo na cidade de São Paulo durante o verão de 1977. São Paulo, 1977. (Tese de Livre-docência - Faculdade de Medicina Veterinária e Zootecnia USP).

12.ROGICK, F.A. Produção higiênica do leite. Rev. ILCT, Juiz de Fora, 37 (221): 35-8, 1982.

13.SȦ, F.V. O leite $e$ seus produtos. $4 a ̣$ ed. Lisboa, Livraria Clássica, 1978.

14.SAMAGH, B.S. \& CUNNINGHAM, J.D. Numerical taxonomy of the Genus pseudomonas from milk products. J. Dairy Sci., 55 : 19-24, 1972.

15.VIEIRA, S.D.A. Os microrganismos como indicadores de qualidade. Rev. ILCT, Juiz de Fora, 31 (185): 19-21, 1976.

Recebido para publicação em 09/06/1983.

Reapresentado em 23/08/1984. Aprovado pare publicação em 21/09/1984. 